\title{
The association between maternal dietary micronutrient intake and neonatal anthropometry - secondary analysis from the ROLO study
}

\author{
Mary K Horan', Ciara A McGowan', Eileen R Gibney², Jean M Donnelly ${ }^{1}$ and Fionnuala M McAuliffe ${ }^{1 *}$
}

\begin{abstract}
Background: Micronutrients are necessary for fetal growth. However increasingly pregnant women are nutritionally replete and little is known about the effect of maternal micronutrient intakes on fetal adiposity in mothers with increased BMI. The aim of this study was to examine the association of maternal dietary micronutrient intake with neonatal size and adiposity in a cohort at risk of macrosomia.
\end{abstract}

Methods: This was a cohort analysis of 554 infants from the ROLO study. Three day food diaries from each trimester were collected. Neonatal weight, length, circumferences and skinfold thicknesses were measured at birth. Multiple linear regression was used to identify associations between micronutrient intakes and neonatal anthropometry.

Results: Birthweight was negatively associated with maternal trimester 3 vitamin D intake and positively associated with trimester 3 vitamin B12 intake R2adj $19.8 \%$ ( $F=13.19, p<0.001)$. Birth length was positively associated with trimester 3 magnesium intake R2adj $12.9 \%$ ( $F=8.06, p<0.001$ ). In terms of neonatal central adiposity; abdominal circumference was positively associated with maternal trimester 3 retinol intake and negatively associated with trimester 3 vitamin $E$ and selenium intake R2adj $11.9 \%(F=2.93, p=0.002)$, waist:length ratio was negatively associated with trimester 3 magnesium intake R2adj $20.1 \%(F=3.92, p<0.001)$ and subscapular:triceps skinfold ratio was negatively associated with trimester 1 selenium intake R2adj7.2\% ( $F=2.00, p=0.047$ ).

Conclusions: Maternal micronutrient intake was associated with neonatal anthropometry even in women not at risk of malnutrition. Further research is necessary to determine optimal micronutrient intake in overweight and obese pregnant women.

Trial registration: Current Controlled Trials ISRCTN54392969.

Keywords: Maternal nutrition, Micronutrients, Pregnancy, Neonatal adiposity, Fetal programming

\section{Introduction}

Micronutrients are necessary for normal growth and development of the fetus and deficiencies have been found to be associated with intrauterine growth retardation and small for gestational age (SGA) infants [1, 2]. In developing countries, supplementation with single [3] or multiple [4] micronutrients has been found to increase birthweight and reduce risk of SGA. However in the developed world, where pregnant women are nutritionally replete and increasingly over-nourished with the

\footnotetext{
*Correspondence: fionnuala.mcauliffe@ucd.ie

'UCD Obstetrics and Gynaecology, School of Medicine and Medical Science, University College Dublin, National Maternity Hospital, Dublin 2, Ireland Full list of author information is available at the end of the article
}

risk of macrosomia (birthweight $>4 \mathrm{~kg}$ or $>95$ th centile) increasing, little is known about micronutrient intakes in pregnant women in relation to fetal size and adiposity. The prevalence of overweight and obesity has increased in women of childbearing age and is associated with increased levels of offspring macrosomia, childhood and later-life overweight and obesity which is thought to occur through metabolic programming [5]. In addition, levels of inflammation naturally increase during pregnancy, mediated by the placenta. The combination of pregnancy and maternal overweight or obesity leads to a chronic inflammatory environment which is thought to affect the fetus indirectly (as cytokines are negligibly directly transferred across the placenta) by increasing 
glucose and lipid availability $[5,6]$. The increased availability of glucose and lipids results in increased fetal growth and fat deposition [6]. Micronutrients have many functions, for example some may be involved in drugnutrient interactions, antioxidant processes, interactions with intercellular signalling proteins, transcriptional regulation, cell proliferation, platelet aggregation and monocyte adhesion as well as other as yet unknown functions $[7,8]$. In addition, there appears to be a synergistic action of micronutrients in food both with each other and with other food components [9]. Finally, micronutrients may also act simply as markers of healthy overall diet and lifestyle confounding the relationship between their mechanisms of action and health outcomes [10]. Due to the multiple possible mechanisms of action, some of which have not fully been uncovered, and to the fact that micronutrients alone may not be resulting in certain health benefits with which they are associated, but rather the health behaviours their consumers undertake, the effect of dietary consumption of micronutrients is not yet fully understood and supplementation with these micronutrients does not always give the expected result [10].

Animal models have shown that micronutrient deficiency may increase offspring adiposity at birth. Antioxidant supplementation has been found by one study to reduce the effect of maternal obesity on neonatal adiposity in rats [11]. Another study found that maternal antioxidant supplementation also reduced the inflammatory destruction of murine fetal pancreatic $\beta$-cells reducing development of type II diabetes [12]. Vitamin D deficiency has similarly been found to be associated with increased risk of gestational diabetes in human studies [13] however human clinical trials are ongoing to determine causality. There remains a paucity of data on the effect of micronutrient intakes on human offspring adiposity, except in the prevention of low birthweight [14]. Therefore, the aim of this study was to examine the influence of maternal dietary micronutrient intake in pregnancy on neonatal weight, length and adiposity using a cohort at risk of macrosomia from the ROLO (Randomised cOntrol trial of LOw glycaemic index diet versus no dietary intervention to prevent recurrence of fetal macrosomia) study [15].

\section{Methods}

Five hundred forty-two mother and infant pairs from the ROLO study were included in this analysis. The ROLO study was a randomised control trial of 800 secundigravid women with a previous macrosomic baby $(>4 \mathrm{~kg})$ randomised to receive low glycaemic index (GI) dietary advice versus usual care (no dietary advice) to reduce recurrence of macrosomia [16]. The ROLO study was carried out at the National Maternity Hospital, Ireland between January 2007 and January 2011 and detailed methodology and results have previously been published [15]. In brief; the primary outcome, a reduction in birthweight was not achieved and the secondary outcomes, a reduction in gestational weight gain and glucose intolerance, were achieved. Low GI dietary advice was given at week 14 of pregnancy while demographic, well-being and lifestyle questionnaires were returned by 28 weeks gestation. Three-day food diaries were completed at each trimester of pregnancy and used to determine the glycaemic index and glycaemic load of the mothers' diets. The control group received routine antenatal care which did not involve dietary advice. This study was conducted according to the guidelines laid down in the Declaration of Helsinki and all procedures involving patients were approved by the National Maternity Hospital, Ireland ethics committee. Written informed maternal consent was obtained from all participants. The work presented here will use the dietary and anthropometric data from the ROLO study in order to carry out a secondary analysis examining the association of maternal micronutrient intake and neonatal size and adiposity.

\section{Inclusion and exclusion criteria}

Participants were secundigravid women who had previously given birth to a macrosomic baby $(>4 \mathrm{~kg})$. They were required to have sufficient literacy and fluency in the English language to understand the intervention and be capable of completing questionnaires. Women were included if they were over 18 years old and free from underlying health conditions and if they had healthy, singleton pregnancies without any intrauterine growth abnormalities.

\section{Maternal demographics and lifestyle}

Of the 800 participants of the ROLO study, 759 completed the original trial and had their infants' anthropometry measured at birth. Of these, 542 completed and returned all questionnaires and food diaries. Questionnaires completed in the first half of pregnancy explored various background socioeconomic and sociodemographic, and lifestyle variables. Questions from SLAN (Survey of Lifestyle, Attitudes and Nutrition in Ireland) [17] relating to lifestyle habits were completed at this time, including questions on number of $20 \mathrm{~min}$ intervals of mild, moderate and strenuous physical activity per week and on number of days per week walking for over $30 \mathrm{~min}$, on smoking and alcohol consumption, on educational attainment and on supplement use.

\section{Maternal and neonatal anthropometry}

Maternal weight $(\mathrm{kg})$, height $(\mathrm{cm})$ and mid-upper arm circumference $(\mathrm{cm})$ were measured at the first antenatal consultation and BMI was calculated. Maternal weight was also measured at each subsequent consultation and gestational weight gain was calculated. 
Neonatal weight $(\mathrm{kg})$, length $(\mathrm{cm})$, mid-upper arm, abdominal, hip and thigh circumference $(\mathrm{cm})$, and biceps, triceps, subscapular and thigh skinfold ( $\mathrm{mm}$ ) measurements were taken at birth. Weight and length were measured for all 542 neonates while other anthropometric measurements were available for 266 neonates as these measurements began to be taken later in the study. Waist:hip, waist:length and subscapular skinfold:triceps skinfold ratios were calculated as were sum of triceps and subscapular skinfold thicknesses and sum of all skinfold thicknesses were in order to measure neonatal adiposity. The most commonly reported anthropometric parameters, "weight" and "length", are very limited measures of adiposity which give no information on body fat distribution. Therefore, the more in-depth measurements above were used. Circumferences and skinfolds describe body weight distribution with skinfolds giving a measure of subcutaneous fat. Multiple-site skinfolds have been found to be more accurate than single site skinfolds and subscapular-to-triceps skinfold ratio measurement has been found to be reflective of central adiposity in children and correlates well with BMI and waist circumference [18, 19]. Waist:height ratio has been found to be a good measure of central adiposity in adults and children with a ratio of $\geq 0.5$ indicating excess central adiposity [20]. A study by Brambilla et al. found it to be a better measure of adiposity than waist circumference or BMI in children and adolescents [21]. Waist circumference to height ratio has also been found to be capable of identifying children with increased cardiometabolic risk factors with some studies [22, 23] finding it a better identifier of cardiovascular disease risk than BMI.

\section{Maternal dietary intake}

Three-day food diaries were completed at each trimester of pregnancy and used to determine maternal energy and micronutrient intake. Micronutrient intake during each trimester of pregnancy was examined separately and adjusted for maternal energy intake.

All food diaries and food frequency questionnaires were entered by a trained dietitian with the use of the household measures and UK Food Standards Agency average portion sizes [24]. Food Diaries were analysed using Tinuviel WISP software, version 3.0, in which the food composition tables used are derived from the 6th edition of McCance and Widdowson's Food Composition Tables. Underreporting was examined using Goldberg ratios i.e. the ratio of energy intake to estimated basal metabolic rate. Basal metabolic rate was calculated using Schofield equations and a Goldberg ratio of $\leq 0.9$ was used to identify definite underreporters $[25,26]$.
Vitamin and mineral supplement use was reported as a binary yes/no answer in questionnaires.

\section{Statistical analysis}

Statistical analysis was completed using SPSS (Statistical Package for the Social Sciences) software version 20.0. Statistical analyses involved correlations, independent sample t-tests and ANOVA and simple and multiple linear regression modelling. The intervention and control groups were analysed both separately and together to ensure all results were representative of both groups. Since there was no difference in neonatal anthropometry except for thigh circumference [27] and waist: length ratio between the control and intervention groups, groups were analysed together for final analysis but group was controlled for in all final models. Micronutrients were examined per $10 \mathrm{MJ}$ energy. Associations between macro- and micro-nutrients and neonatal anthropometry were first examined using correlations. Variables that were found to be significantly associated with neonatal anthropometry were further analysed using simple linear regression, then input into the final multiple regression model for well-being using a forced enter and backwards stepwise approach. While the focus of this analysis was to examine the associations between maternal micronutrient intakes and neonatal adiposity, macronutrients were also examined in order to determine whether micronutrients were independently associated with offspring adiposity or were simply acting as markers of macronutrient intakes. Both macronutrients and micronutrients that were statistically significantly associated with neonatal anthropometry using simple linear regression were included in a backwards stepwise multiple regression block resulting in any nonsignificant variables being discarded from the model in a stepwise manner. Variables known to affect neonatal size (maternal education level as a marker of socioeconomic status, pre-pregnancy BMI, length of gestation and neonate gender), were controlled for using a forced enter multiple regression block in all models. As mentioned, membership of the control or intervention group was also included in these models. Underreporting of dietary intake was addressed by removing definite underreporters (Goldberg ratio $\leq 0.9$ ) from the multiple linear regression analysis. Supplement use was also controlled for in the final multiple linear regression models. Multiple linear regression resulted in a best and final model and models that were statistically significant overall $(p<0.05)$ were chosen as those which best predicted neonatal adiposity. Compliance with Irish recommended dietary allowances [28] was also examined using the population compliance method [29]. 


\section{Sample size for maternal micronutrient effect on neonatal skinfolds}

We used information from a previous publication [30] to obtain a standard deviation for a sum of skinfolds (SS+TR) measure, and to obtain regression analysis effect sizes for a generic standardised predictor variable $(\mathrm{SD}=1)$. The sample sizes to detect an effect in linear regression of SS+TR on a generic micronutrient level are presented below. The predictor (micronutrient) is assumed standardised to have a standard deviation of 1 . The slope therefore reflects the detectable difference in SS+TR, for a 1 SD difference in the predictor, at a power of $80 \%$ with a type I error rate of 0.05 :

\begin{tabular}{ll}
\hline Slope $(\mathrm{mm})$ & Sample size (total) \\
0.5 & 575 \\
1 & 145 \\
1.5 & 66 \\
2 & 38 \\
\hline
\end{tabular}

From Donahue et al., the observed effect of a 1 SD difference in each predictor on SS+TR reached as high as 0.64 (Total n-6 fatty acids), 0.81 (n-6:n-3 ratio), and 0.61 (LA:ALA ratio) all of which should be detectable in a sample of at least 387 subjects.

\section{Results}

\section{Demographics}

Maternal characteristics are displayed in Table 1 with a comparison of participants and those lost to follow-up. $91.4 \%$ of the 542 women were of "white Irish", $6.7 \%$ of "white other", $0.3 \%$ of "African", $0.5 \%$ of "Chinese", $0.1 \%$ of "Indian" and $1.0 \%$ of "Filipino/South East Asian" ethnicity. $78.1 \%$ of the women had achieved 3rd level education while $21.9 \%$ had not. $4.0 \%$ of women reported smoking in early pregnancy while $96.0 \%$ reported being non-smokers. Participants were significantly older and had a lower early pregnancy weight and BMI than those lost to follow up but there was no difference in gestational weight gain or neonatal anthropometry between the groups. A comparison of maternal and infant characteristics of infants with and without circumference and skinfold measurements was also made (Table 2). No difference in maternal characteristics or neonatal weight or length was observed between those with and without these measurements.

\section{Maternal dietary intake and underreporting}

Adequacy of dietary maternal micronutrient intake in each trimester when compared to Irish RDA's for pregnancy [28] is displayed in Table 3 The percentage of participants who met the RDA's for pregnancy was particularly low for folate, vitamin C and vitamin D (9.8 \% in trimester 1, $21.3 \%$ in trimester 2 and $7.2 \%$ in trimester 3 respectively). Maternal dietary intakes and a comparison of study groups is displayed in Additional file 1: Table S1. Underreporting was found to affect the associations observed in the final multiple linear regression models. Therefore underreporters were removed from this analysis (Table 4).

\section{Associations between maternal micronutrient intake and neonatal anthropometry}

Statistically significant multiple linear regression models for the association between maternal micronutrient intakes and neonatal anthropometry are displayed in Table 4 and were as follows: birthweight was negatively associated with maternal trimester 3 vitamin $\mathrm{D}$ intake and positively associated with trimester 3 vitamin B12 intake R2adj $19.8 \%(\mathrm{~F}=13.19, p<0.001)$, birth length was positively associated with trimester 3 magnesium intake R2adj $12.9 \%(\mathrm{~F}=8.06, p<0.001)$, neonatal abdominal circumference was positively associated with maternal trimester 3 retinol intake and negatively associated with trimester 3 vitamin $\mathrm{E}$ and selenium intake R2adj $11.9 \%(F=2.93, p=0.002)$, neonatal waist:length ratio was negatively associated with trimester 3 magnesium intake R2adj $20.1 \%(\mathrm{~F}=3.92, p<0.001)$, SSF:TSF ratio was negatively associated with trimester 1 selenium intake $\mathrm{R} 2 \mathrm{adj} 7.2 \%(\mathrm{~F}=2.00, p=0.047)$. There was no association between reported maternal vitamin or mineral supplement use during pregnancy and any of the neonatal anthropometric measurements, ratios or sums of skinfold thicknesses and therefore all micronutrient associations described are from dietary intake alone.

\section{Discussion}

The main findings of this analysis which examined the associations between neonatal anthropometry and micronutrient intakes were that birthweight was negatively associated with trimester 3 vitamin $\mathrm{D}$ intake and positively associated with trimester 3 vitamin B12 intake while birth length was positively associated with trimester 3 vitamin B12 intake. Abdominal circumference was positively associated with maternal trimester 3 retinol intake and negatively associated with trimester 3 vitamin $E$ and selenium intake. When ratios for estimation of neonatal adiposity were calculated, it was found that the subscapular:triceps skinfold thickness ratio, a measure of central adiposity, was negatively associated with trimester 1 selenium intake while the waist circumference:length ratio, another measure of central adiposity, was negatively associated with trimester 3 magnesium intake. Our finding that birthweight was negatively associated with trimester 3 vitamin D intake is contrary to to the findings other studies [31, 32]. This may be due, in part, to the nature of our cohort, in 
Table 1 General maternal background characteristics during pregnancy and neonatal anthropometry with comparison of participants and those that were lost to follow-up

\begin{tabular}{|c|c|c|c|c|c|c|c|}
\hline & & Lost to f & & & Participa & & \\
\hline & $\mathrm{N}$ & Mean & SD & $\mathrm{n}$ & Mean & SD & $p$ \\
\hline Mother age (yrs) & 222 & 32.17 & 4.75 & 483 & 32.87 & 3.93 & 0.041 \\
\hline Mother height $(\mathrm{cm})$ & 240 & 165.10 & 16.58 & 542 & 165.27 & 11.86 & 0.868 \\
\hline Mother weight (kg) & 238 & 76.48 & 16.52 & 541 & 72.38 & 12.94 & $<0.001$ \\
\hline Mother BMI $\left(\mathrm{kg} / \mathrm{m}^{2}\right)$ & 237 & 27.61 & 6.01 & 540 & 26.30 & 4.38 & 0.001 \\
\hline Gestational Weight Gain (kg) & 93 & 12.87 & 5.07 & 273 & 13.39 & 4.55 & 0.359 \\
\hline Days per week walking $\geq 30 \mathrm{~min}^{\mathrm{b}}$ & 94 & 3.43 & 1.81 & 427 & 3.48 & 1.79 & 0.772 \\
\hline Moderate activity (min per week) & 57 & 59.65 & 43.01 & 309 & 66.15 & 43.45 & 0.299 \\
\hline Neonatal weight $(\mathrm{kg})$ & 207 & 4.01 & 604.18 & 542 & 4.02 & 4.58 & 0.633 \\
\hline Neonatal length $(\mathrm{cm})$ & 184 & 52.74 & 2.56 & 454 & 52.75 & 2.33 & 0.964 \\
\hline Neonatal MUAC $(\mathrm{cm})$ & 43 & 12.57 & 1.23 & 223 & 12.39 & 1.51 & 0.475 \\
\hline Neonatal abdominal $\operatorname{circ}^{\mathrm{d}}(\mathrm{cm})$ & 43 & 33.47 & 2.26 & 222 & 33.40 & 2.11 & 0.844 \\
\hline Neonatal waist circ ${ }^{d}$.hip ratio & 42 & 33.43 & 2.27 & 221 & 33.63 & 2.32 & 0.606 \\
\hline Neonatal thigh $\operatorname{circ}^{d}(\mathrm{~cm})$ & 43 & 16.23 & 1.44 & 222 & 16.16 & 1.67 & 0.801 \\
\hline Neonatal biceps skinfold (mm) & 33 & 6.85 & 1.72 & 186 & 6.78 & 1.46 & 0.806 \\
\hline Neonatal triceps skinfold (mm) & 33 & 6.94 & 1.50 & 186 & 7.00 & 1.52 & 0.822 \\
\hline Neonatal subscapular skinfold (mm) & 33 & 7.14 & 2.07 & 186 & 6.90 & 1.49 & 0.423 \\
\hline Neonatal thigh skinfold (mm) & 33 & 8.08 & 2.20 & 186 & 7.90 & 1.76 & 0.605 \\
\hline Neonatal waist:length circ ${ }^{d}$ ratio & 37 & 0.63 & 0.04 & 182 & 0.64 & 0.05 & 0.775 \\
\hline Neonatal SOSF $(\mathrm{mm})$ & 33 & 29.00 & 6.45 & 186 & 28.58 & 5.18 & 0.677 \\
\hline Neonatal sum TSF $^{f}$ and SSF${ }^{g}(\mathrm{~mm})$ & 33 & 14.08 & 3.19 & 186 & 13.90 & 2.69 & 0.736 \\
\hline Neonatal SSF :TSF ${ }^{f}$ ratio & 33 & 1.04 & 0.23 & 186 & 1.00 & 0.19 & 0.332 \\
\hline Neonatal waist:hip circ $^{d}$ ratio & 42 & 1.00 & 0.05 & 221 & 1.00 & 0.06 & 0.312 \\
\hline
\end{tabular}

" $\mathrm{n}$ " denotes number, $p<0.05$ was considered statistically significant (2-tailed significance generated from independent sample t-tests)

Abbreviations: ${ }^{\mathrm{a} B M I}$ body mass index, ${ }^{\mathrm{b}}$ min minutes, ${ }^{\mathrm{C}} \mathrm{MUAC}$ mid-upper arm circumference, ${ }^{\mathrm{d}}$ circ circumference, ${ }^{\mathrm{e}} \mathrm{SOSF}$ sum of skinfolds, ${ }^{\mathrm{f}} \mathrm{TSF}$ triceps skinfold, ${ }^{\mathrm{g}} \mathrm{SSF}$ subscapular skinfold

which there was a high prevalence of macrosomia as a US randomised control trial of vitamin $\mathrm{D}$ supplementation in pregnancy by Wagner et al. [33] found that, when macrosomia was examined, the group supplemented with the highest doses of vitamin $\mathrm{D}$ gave birth to significantly more infants of normal birthweight than those supplemented with lower doses.

Maternal trimester 3 vitamin B12 intake was positively associated with birthweight. This effect on fetal growth is thought to be due to the activity of vitamin B12 as a

Table 2 Comparison of maternal and offspring characteristics between participants with and without skinfold measurements

\begin{tabular}{|c|c|c|c|c|c|c|c|}
\hline & \multicolumn{3}{|c|}{ No skinfolds } & \multicolumn{3}{|c|}{ Skinfolds } & \multirow[b]{2}{*}{$P$} \\
\hline & $n$ & Mean & SD & $n$ & Mean & SD & \\
\hline Mother age (yrs) & 309 & 32.89 & 3.82 & 176 & 32.85 & 4.11 & 0.905 \\
\hline Mother height $(\mathrm{cm})$ & 321 & 165.71 & 11.32 & 227 & 164.66 & 12.45 & 0.304 \\
\hline Mother weight (kg) & 322 & 72.21 & 13.05 & 226 & 72.81 & 12.86 & 0.591 \\
\hline Mother BMI $\left(\mathrm{kg} / \mathrm{m}^{2}\right)$ & 320 & 26.12 & 4.39 & 226 & 26.61 & 4.40 & 0.200 \\
\hline Gestational weight gain (kg) & 152 & 13.18 & 4.37 & 121 & 13.65 & 4.78 & 0.399 \\
\hline Days per week walking $\geq 30 \mathrm{~min}^{2}$ & 255 & 3.51 & 1.85 & 178 & 3.43 & 1.71 & 0.637 \\
\hline Moderate activity (min per week) & 191 & 65.97 & 44.67 & 122 & 65.74 & 41.50 & 0.963 \\
\hline Birth_weight (kg) & 319 & 4.00 & 4.55 & 223 & 4.06 & 459.42 & 0.127 \\
\hline BirthLength (cm) & 282 & 52.66 & 2.44 & 176 & 52.89 & 2.18 & 0.316 \\
\hline
\end{tabular}


Table 3 Micronutrient RDAs for pregnancy and proportion of women meeting these RDAs with comparison of frequency of meeting RDAs between the control and intervention groups

\begin{tabular}{|c|c|c|c|c|}
\hline & RDA & $\mathrm{n}$ meeting RDA & $\%$ meeting RDA & $p$-value \\
\hline Trimester 1 Riboflavin & $1.3 \mathrm{mg} / \mathrm{d}$ & 460 & 100 & 1.0 \\
\hline Trimester 2 Riboflavin & $1.6 \mathrm{mg} / \mathrm{d}$ & 466 & 100 & 1.0 \\
\hline Trimester 3 Riboflavin & $1.6 \mathrm{mg} / \mathrm{d}$ & 461 & 100 & 1.0 \\
\hline Trimester 1 Thiamine & 100ug/MJ & 460 & 100 & 1.0 \\
\hline Trimester 2 Thiamine & 100ug/MJ & 466 & 100 & 1.0 \\
\hline Trimester 3 Thiamine & 100ug/MJ & 461 & 100 & 1.0 \\
\hline Trimester 1 Niacin & $1.6 \mathrm{mg} / \mathrm{MJ}$ & 460 & 100 & 1.0 \\
\hline Trimester 2 Niacin & $1.6 \mathrm{mg} / \mathrm{MJ}$ & 466 & 100 & 1.0 \\
\hline Trimester 3 Niacin & $1.6 \mathrm{mg} / \mathrm{MJ}$ & 461 & 100 & 1.0 \\
\hline Trimester 1 Vitamin C & $60 \mathrm{mg} / \mathrm{d}$ & 238 & 51.7 & 0.008 \\
\hline Trimester 2 Vitamin C & $80 \mathrm{mg} / \mathrm{d}$ & 121 & 26.0 & 0.026 \\
\hline Trimester 3 Vitamin C & $80 \mathrm{mg} / \mathrm{d}$ & 98 & 21.3 & 0.189 \\
\hline Trimester 1 Vitamin B6 & 15ug/g protein & 460 & 100 & 1.0 \\
\hline Trimester 2 Vitamin B6 & 15ug/g protein & 466 & 100 & 1.0 \\
\hline Trimester 3 Vitamin B6 & 15ug/g protein & 461 & 100 & 1.0 \\
\hline Trimester 1 Folate & $500 \mathrm{ug} / \mathrm{d}$ & 45 & 9.8 & 0.077 \\
\hline Trimester 2 Folate & $500 \mathrm{ug} / \mathrm{d}$ & 37 & 7.9 & 0.594 \\
\hline Trimester 3 Folate & $500 \mathrm{ug} / \mathrm{d}$ & 54 & 11.7 & 0.145 \\
\hline Trimester 1 Vitamin B12 & $1.4 \mathrm{ug} / \mathrm{d}$ & 460 & 100 & 1.0 \\
\hline Trimester 2 Vitamin B12 & $1.6 \mathrm{ug} / \mathrm{d}$ & 466 & 100 & 1.0 \\
\hline Trimester 3 Vitamin B12 & $1.6 \mathrm{ug} / \mathrm{d}$ & 461 & 100 & 1.0 \\
\hline Trimester 1 Vitamin D & $10 \mathrm{ug} / \mathrm{d}$ & 8 & 1.7 & $N / A^{*}$ \\
\hline Trimester 2 Vitamin D & $10 \mathrm{ug} / \mathrm{d}$ & 12 & 2.6 & $N / A^{*}$ \\
\hline Trimester 3 Vitamin D & $10 \mathrm{ug} / \mathrm{d}$ & 33 & 7.2 & 0.965 \\
\hline Trimester 1 Calcium & $800 \mathrm{mg} / \mathrm{d}$ & 460 & 100 & 1.0 \\
\hline Trimester 2 Calcium & $1200 \mathrm{mg} / \mathrm{d}$ & 228 & 48.9 & 0.809 \\
\hline Trimester 3 Calcium & $1200 \mathrm{mg} / \mathrm{d}$ & 264 & 57.3 & 0.482 \\
\hline Trimester 1 Potassium & $3100 \mathrm{mg} / \mathrm{d}$ & 335 & 72.8 & 0.449 \\
\hline Trimester 2 Potassium & $3100 \mathrm{mg} / \mathrm{d}$ & 368 & 80.0 & 0.010 \\
\hline Trimester 3 Potassium & $3100 \mathrm{mg} / \mathrm{d}$ & 373 & 80.9 & 0.004 \\
\hline Trimester 1 Iron & $14 \mathrm{mg} / \mathrm{d}$ & 247 & 53.7 & 0.003 \\
\hline Trimester 2 Iron & $15 \mathrm{mg} / \mathrm{d}$ & 178 & 38.2 & 0.028 \\
\hline Trimester 3 Iron & $15 \mathrm{mg} / \mathrm{d}$ & 190 & 41.2 & 0.021 \\
\hline Trimester 1 Zinc & $7 \mathrm{mg} / \mathrm{d}$ & 460 & 100 & 1.0 \\
\hline Trimester 2 Zinc & $7 \mathrm{mg} / \mathrm{d}$ & 466 & 100 & 1.0 \\
\hline Trimester 3 Zinc & $7 \mathrm{mg} / \mathrm{d}$ & 461 & 100 & 1.0 \\
\hline Trimester 1 Selenium & $55 \mathrm{ug} / \mathrm{d}$ & 299 & 65.0 & 0.005 \\
\hline Trimester 2 Selenium & $55 \mathrm{ug} / \mathrm{d}$ & 297 & 63.7 & 0.005 \\
\hline Trimester 3 Selenium & $55 \mathrm{ug} / \mathrm{d}$ & 274 & 59.4 & 0.036 \\
\hline Trimester 1 lodine & $130 \mathrm{ug} / \mathrm{d}$ & 460 & 100 & 1.0 \\
\hline Trimester 2 lodine & $130 \mathrm{ug} / \mathrm{d}$ & 466 & 100 & 1.0 \\
\hline Trimester 3 lodine & $130 \mathrm{ug} / \mathrm{d}$ & 461 & 100 & 1.0 \\
\hline Trimester 1 Sodium & $2400 \mathrm{mg} / \mathrm{d}$ & 353 & 76.7 & 0.131 \\
\hline
\end{tabular}


Table 3 Micronutrient RDAs for pregnancy and proportion of women meeting these RDAs with comparison of frequency of meeting RDAs between the control and intervention groups (Continued)

\begin{tabular}{llllr}
\hline Trimester 2 Sodium & $2400 \mathrm{mg} / \mathrm{d}$ & 364 & 78.1 & 0.365 \\
Trimester 3 Sodium & $2400 \mathrm{mg} / \mathrm{d}$ & 335 & 72.7 & 0.003 \\
Trimester 1 Vitamin A & $600 \mathrm{ug} / \mathrm{d}$ & 119 & 25.9 & $<0.001$ \\
Trimester 2 Vitamin A & $700 \mathrm{ug} / \mathrm{d}$ & 48 & 10.3 & 0.881 \\
Trimester 3 Vitamin A & $700 \mathrm{ug} / \mathrm{d}$ & 119 & 25.8 & $<0.001$
\end{tabular}

Based on Irish RDAs [28]. Insufficient data to provide recommendations for: $ß$ Carotene and other carotenoids Pantothenic acid, Vitamin K, Magnesium, Molybdenum, Manganese, Biotin, Fluoride, Chloride, Chromium and Vitamin E. Definite underreporters excluded (Goldberg Ratio $\leq 0.9)$. The population compliance method was used to determine frequency of compliance with RDAs [35]. Chi-squared tests used to compare frequency of compliance with RDAs between the control and intervention groups. *N/A as zero women in the intervention group met the RDA for vitamin D in trimesters 1 or 2

coenzyme in the conversion of homocysteine to methionine which is in turn converted to S-adenosylmethionine. In vitamin B12 deficiency, this reaction is reduced resulting in increased levels of homocysteine which alters the placental vascular endothelium leading to fetal growth restriction [34, 35]. Levels of S-adenosylmethionine are also concomitantly reduced, decreasing the level of DNA methylation and are thereby thought to epigenetically reduce fetal growth [36, 37]. Study results been conflicting regarding the association of vitamin B12 and birthweight

Table 4 Maternal micronutrient intakes associated with neonatal anthropometry- final models

\begin{tabular}{|c|c|c|c|c|c|c|}
\hline & B & SEB & $p$ & $R^{2}$ adj & $f$ & $p$ \\
\hline \multicolumn{7}{|l|}{ Birthweight } \\
\hline Trimester 2 vitamin D/10 MJ & -19.62 & 6.558 & 0.003 & 0.198 & 13.19 & $<0.001$ \\
\hline Trimester 3 vitamin B12/10 MJ & 104.73 & 33.349 & 0.002 & & & \\
\hline \multicolumn{7}{|l|}{ Birth length } \\
\hline Trimester 3 magnesium/10 MJ & 0.01 & 0.002 & 0.010 & 0.129 & 8.06 & $<0.001$ \\
\hline \multicolumn{7}{|l|}{ Abdominal circumference } \\
\hline Trimester 3 selenium/10 MJ & -0.02 & 0.008 & 0.028 & & & \\
\hline Trimester 3 retinol/10 MJ & 0.001 & 0.001 & 0.020 & 0.119 & 2.93 & 0.002 \\
\hline Trimester 3 vitamin E/10 MJ & -0.11 & 0.053 & 0.039 & & & \\
\hline \multicolumn{7}{|l|}{ Thigh circumference } \\
\hline Trimester 3 magnesium/10 MJ & -0.01 & 0.002 & 0.018 & 0.052 & 2.16 & 0.042 \\
\hline \multicolumn{7}{|l|}{ Hip circumference } \\
\hline Trimester 3 vitamin B6/10 MJ & 1.05 & 0.329 & 0.002 & 0.100 & 3.31 & 0.003 \\
\hline \multicolumn{7}{|l|}{ Mid-upper arm circumference } \\
\hline Trimester 2 sodium/10 MJ & -0.0002 & 0.0001 & 0.081 & & & \\
\hline Trimester 2 vitamin B6/10 MJ & -0.23 & 0.052 & $<0.001$ & 0.260 & 6.58 & \\
\hline Trimester 3 selenium/10 MJ & -0.01 & 0.005 & 0.002 & & & $<0.001$ \\
\hline \multicolumn{7}{|l|}{ Subscapular skinfold thickness } \\
\hline Trimester 1 vitamin C/10 MJ & 0.004 & 0.002 & 0.024 & 0.088 & 2.39 & 0.021 \\
\hline Trimester 1 vitamin B12/10 MJ & 0.50 & 0.246 & 0.045 & & & \\
\hline \multicolumn{7}{|l|}{ Subscapular:triceps skinfold ratio } \\
\hline Trimester 1 selenium/10 MJ & -0.002 & 0.001 & 0.026 & & & \\
\hline Trimester 2 iodine/10 MJ & 0.0003 & 0.0002 & 0.092 & 0.072 & 2.00 & 0.047 \\
\hline Trimester 2 retinol/10 MJ & $9.632 \mathrm{E}-05$ & 0.00005 & 0.050 & & & \\
\hline \multicolumn{7}{|l|}{ Waist circumference:length ratio } \\
\hline Trimester 2 magnesium/10 MJ & -0.0003 & 0.0001 & 0.001 & 0.201 & 3.92 & $<0.001$ \\
\hline
\end{tabular}

Multiple linear regression analysis controlling for maternal education, pre-pregnancy BMl, length of gestation (d), neonate gender, study group (intervention/control), supplement use (yes/no) and significantly associated macronutrient intake (\%TE). Definite underreporters (Goldberg ratio $\leq 0.9)$ removed. $p<0.05$ considered statistically significant 
with some reporting a positive association [38-41] and others observing no such association [42-46]. A recent study which did not observe an association between birth weight or length and maternal vitamin B12 levels found that when the ratio of maternal plasma folate to vitamin B12 was examined there was an inverse association with neonatal weight, length, head circumference and chest circumference but no association was observed with neonatal triceps or subscapular skinfold thickness [43]. No such inverse association was observed in our analysis, however. Another study reported a positive association between birthweight and absolute vitamin B12 and also observed a further adverse effect on birthweight of folate supplementation in women with poor vitamin B12 status [38]. Therefore, increased folate levels resulting in increased homocysteine levels when vitamin B12 is ratelimiting may negatively affect birthweight.

The positive association of maternal trimester $3 \mathrm{mag}$ nesium intake with birth length may be due to the role of magnesium in skeletal growth with the greatest rate of mineral accretion occurring in the 3rd trimester [47]. A study by Doyle et al. [48] found that magnesium intake of 513 women in trimester 1 was similarly associated with birth length but that magnesium supplementation in later trimesters did not affect infant size. Similarly, the ALSPAC study found that bone mineral density and height of 9 year old children was associated with maternal magnesium intake during late pregnancy [49] and another Tasmanian study found the bone mass of 8 year old children was positively associated with maternal magnesium intake in trimester 3 [50]. This was hypothesised however to be mediated by fetal programming of growth by maternal diet during pregnancy rather than by fetal bone mineralisation $[49,50]$. The finding that trimester 2 magnesium intake was negatively associated with neonatal waist:length circumference, a marker of central adiposity [20], may also due to an association with increased neonatal length. A further possible explanation for this association may be that is a maker of overall healthy diet [51] although maternal BMI and macronutrient intake was controlled for in all of our final models. In addition, there is also evidence that low blood magnesium levels and magnesium deficiency are associated with inflammation in adults and children [52-54], and with insulin insensitivity and metabolic syndrome and consequently central adiposity $[52,55]$.

Selenium was negatively associated with two measures of central adiposity, trimester 3 selenium with the abdominal circumference and trimester 1 selenium with the subscapular:triceps skinfold ratio. The main function of selenium is as an antioxidant due to its incorporation into selenoproteins which have are involved in glutathione peroxidase production and many other anti-inflammatory mechanisms, not all of which are yet understood [56]. Increased selenium levels may modulate selenoprotein gene expression and selenium supplementation has been found to be associated with reduced TNF- $\alpha$ levels in vitro and in vivo [57, 58]. However, selenium can also act through modulating the effect of TNF- $\alpha$ via TNF- $\alpha$ receptors [59] and can up-regulate production of TNF- $\alpha$ in individuals in whom it is under-produced for example individuals at risk of carcinoma [60]. It therefore acts as an antiproliferative agent and is also a component of many enzymes in the body. Low selenium status in pregnancy has been linked with reduced birthweight [61-63] and with gestational diabetes and maternal glucose intolerance [64-66]. Although we found that dietary selenium was negatively associated with central adiposity in this cohort, we did not observe an association with birthweight. Studies exploring the relationship between selenium and birthweight, unlike this study, have examined serum rather than dietary selenium levels and have proposed that oxidative stress in these pregnancies may have resulted in selenium depletion.

Finally, maternal trimester 2 and 3 retinol intakes were positively associated with central adiposity. Low maternal retinol status has been found to be associated with reduced offspring birthweight by several studies [67-70] although other studies have reported opposing results [71-74]. However, as with all micronutrients associated with neonate adiposity in this cohort, the association with neonatal adiposity specifically, rather than just birthweight, has not been reported in the literature to the best of the authors' knowledge.

Limitations of this study were that blood micronutrient levels were not measured although extensive dietary records were obtained from 3-day food diaries at each trimester of pregnancy. Detailed information on micronutrient supplementation in pregnancy was not available as this was a secondary analysis. A further limitation was that we were unable to rule out the possibility of micronutrients synergistic activity as mentioned above. Equally, it is possible that micronutrients may have been acting as markers of improved maternal health behaviours [10] although we attempted to reduce the likelihood of this by controlling for BMI and controlling for any macronutrients associated with neonatal anthropometry in all final models. Finally, an additional limitation was that circumference and skinfold thickness measurements were not available for the full cohort resulting in reduced statistical power of the analysis. No significant difference in maternal or offspring characteristics was observed when infants with and without circumference and skinfold measurements were compared, however. There has been little research into intakes of micronutrients in overweight and obese pregnant women with no studies specifically exploring the association with offspring adiposity and the ROLO study was appropriate for exploration of these associations as there was a high level of overweight (mean BMI in early 
pregnancy $26.3 \mathrm{~kg} / \mathrm{m} 2$ ) and macrosomia (mean birthweight of $4.02 \mathrm{~kg}$ ) in this cohort. Further research is necessary to define such relationships and determine optimum maternal micronutrient intakes for overweight or obese pregnancies.

\section{Conclusions}

Dietary intakes of several micronutrients were poor during pregnancy in women from a developed country. Maternal dietary micronutrient intake is associated with neonatal anthropometry even in women not at risk of malnutrition and further research is necessary to determine optimal micronutrient intake in overweight and obese women.

\section{Additional file}

Additional file 1: Table S1. Maternal Energy and Micronutrient Intakes in Each Trimester of Pregnancy including Comparison of Control and Low Glycaemic Index Intervention Groups. (DOC 119 kb)

\section{Competing interests}

The authors declare that they have no competing interests

\section{Authors' contributions}

$\mathrm{MKH}$ - carried out data analysis and wrote the manuscript, CAMcG- carried out data collection and reviewed the manuscript, ERG-gave advice on study design and carried out manuscript editing and review, JMD carried out manuscript editing and review, FMMcA was responsible for conception of the study, advice on study design and manuscript editing and review. All authors read and approved the final manuscript.

\section{Acknowledgements}

The authors would like to thank Jacinta Byrne, research midwife, who carried out data collection and Ricardo Segurado who gave statistical advice. This study was supported by the Health Research Board Ireland, the Health Research Centre for diet, nutrition and diabetes Ireland, the National Maternity Hospital Medical Fund. The research leading to these results has also received funding from the European Union's Seventh Framework Programme (FP7/2007-2013), project EarlyNutrition under grant agreement no. 289346.

\section{Author details}

${ }^{1}$ UCD Obstetrics and Gynaecology, School of Medicine and Medical Science, University College Dublin, National Maternity Hospital, Dublin 2, Ireland. ${ }^{2}$ UCD Institute of Food and Health, University College Dublin, Dublin 4, Ireland.

Received: 17 March 2015 Accepted: 26 September 2015 Published online: 07 October 2015

\section{References}

1. Mulligan ML, Felton SK, Riek AE, Bernal-Mizrachi C. Implications of vitamin D deficiency in pregnancy and lactation. Am J Obstet Gynecol. 2010:202(5):429. e1-. e9.

2. Scholl TO. Iron status during pregnancy: setting the stage for mother and infant. Am J Clin Nutr. 2005;81(5):1218S-22S.

3. Menendez C, Todd J, Alonso P, Francis N, Lulat S, Ceesay S, et al. The effects of iron supplementation during pregnancy, given by traditional birth attendants, on the prevalence of anaemia and malaria. Trans R Soc Trop Med Hyg. 1994;88(5):590-3.

4. Roberfroid D, Huybregts L, Lanou H, Henry M-C, Meda N, Menten J, et al. Effects of maternal multiple micronutrient supplementation on fetal growth: a double-blind randomized controlled trial in rural Burkina Faso. Am J Clin Nutr. 2008:88(5):1330-40
5. Catalano PM. Obesity and pregnancy - the propagation of a viscous cycle? J Clin Endocrinol Metab. 2003:88(8):3505-6.

6. Catalano PM, Hauguel-De MS. Is it time to revisit the Pedersen hypothesis in the face of the obesity epidemic? Am J Obstet Gynecol. 2011;204(6):479-87.

7. Holst B, Williamson G. Nutrients and phytochemicals: from bioavailability to bioefficacy beyond antioxidants. Curr Opin Biotechnol. 2008;19(2):73-82.

8. Azzi A, Gysin R, Kempná P, Munteanu A, Negis Y, Villacorta L, et al. Vitamin E mediates cell signaling and regulation of gene expression. Ann N Y Acad Sci. 2004;1031(1):86-95

9. Jacobs DR, Gross MD, Tapsell LC. Food synergy: an operational concept for understanding nutrition. Am J Clin Nutr. 2009;89(5):1543S-8S.

10. Woodside JV, McCall D, McGartland C, Young IS. Micronutrients: dietary intake v. supplement use. Proc Nutr Soc. 2005;64(04):543-53.

11. Sen S, Simmons RA. Maternal antioxidant supplementation prevents adiposity in the Offspring of Western Diet-Fed Rats. Diabetes. 2010;59(12):3058-65.

12. Bruin JE, Woynillowicz AK, Hettinga BP, Tarnopolsky MA, Morrison KM, Gerstein $\mathrm{HC}$, et al. Maternal antioxidants prevent $\beta$-cell apoptosis and promote formation of dual hormone-expressing endocrine cells in male offspring following fetal and neonatal nicotine exposure. J Diabetes. 2012;4(3):297-306

13. Aulchenko YS, Struchalin MV, Belonogova NM, Axenovich TI, Weedon MN, Hofman A, et al. Predicting human height by Victorian and genomic methods. Eur J Hum Genet. 2009;17(8):1070-5.

14. Christian P. Micronutrients, birth weight, and survival. Annu Rev Nutr. 2010;30:83-104.

15. Walsh JM, McGowan CA, Mahony R, Foley ME, McAuliffe FM. Low glycaemic index diet in pregnancy to prevent macrosomia (ROLO study): randomised control trial. Br Med J. 2012;345

16. Walsh J, Mahony R, Foley M, Mc AF. A randomised control trial of low glycaemic index carbohydrate diet versus no dietary intervention in the prevention of recurrence of macrosomia. BMC Pregnancy Childbirth. 2010;10(1):16

17. Harrington J, Perry I, Lutomski J, Morgan K, McGee H, Shelley E, et al. SLÁN 2007: survey of lifestyle, attitudes and nutrition in Ireland. Dietary habits of the Irish population. Psychology reports. 2008. p. 6.

18. Moreno LA, Fleta J, Mur L, Feja C, Sarría A, Bueno M. Indices of body fat distribution in Spanish children aged 4.0 to 14.9 years. J Pediatr Gastroenterol Nutr. 1997:25(2):175-81.

19. Moreno L, Rodríguez G, Guillén J, Rabanaque M, León J, Ariño A. Anthropometric measurements in both sides of the body in the assessment of nutritional status in prepubertal children. Eur J Clin Nutr. 2002;56(12):1208-15.

20. McCarthy HD, Ashwell M. A study of central fatness using waist-to-height ratios in UK children and adolescents over two decades supports the simple message-'keep your waist circumference to less than half your height'. Int J Obes. 2006;30(6):988-92.

21. Brambilla P, Bedogni $G$, Heo M, Pietrobelli A. Waist circumference-to-height ratio predicts adiposity better than body mass index in children and adolescents. Int J Obes. 2013;37(7):943-6.

22. Mokha JS, Srinivasan SR, DasMahapatra P, Fernandez C, Chen W, Xu J, et al. Utility of waist-to-height ratio in assessing the status of central obesity and related cardiometabolic risk profile among normal weight and overweight/ obese children: the Bogalusa Heart Study. BMC Pediatr. 2010;10(1):73.

23. Kahn HS, Imperatore G, Cheng YJ. A population-based comparison of BMI percentiles and waist-to-height ratio for identifying cardiovascular risk in youth. J Pediatr. 2005;146(4):482-8.

24. Crawley H, Patel S, Mills A, Great Britain. Ministry of Agriculture F, Food Agency GBFS. Food Portion Sizes. London: Stationery Office; 2002.

25. Goldberg G, Black A, Jebb S, Cole T, Murgatroyd P, Coward W, et al. Critical evaluation of energy intake data using fundamental principles of energy physiology: 1. Derivation of cut-off limits to identify under-recording. Eur J Clin Nutr. 1991;45(12):569-81.

26. Schofield W. Predicting basal metabolic rate, new standards and review of previous work. Hum Nutr Clin Nutr. 1984;39:5-41.

27. Donnelly J, Walsh J, Byrne J, Molloy E, McAuliffe F. Impact of maternal die on neonatal anthropometry: a randomized controlled trial. Paediatr Obes. 2015;10(1):52-6.

28. Ireland FSAO. Recommended dietary allowances for Ireland: nutrition. Dublin: Food Safety Authority of Ireland; 1999.

29. Wearne SJ, Day MJ. Clues for the development of food-based dietary guidelines: how are dietary targets being achieved by UK consumers? Br J Nutr. 1999;81(S1):S119-S26. 
30. Donahue SM, Rifas-Shiman SL, Gold DR, Jouni ZE, Gillman MW, Oken E. Prenatal fatty acid status and child adiposity at age $3 \mathrm{y}$ : results from a US pregnancy cohort. Am J Clin Nutr. 2011;93(4):780-8.

31. Eckhardt $C L$, Gernand $A D$, Roth DE, Bodnar LM. Maternal vitamin D status and infant anthropometry in a US multi-centre cohort study. Ann Hum Biol. 2015:42(3):215-22.

32. Leffelaar ER, Vrijkotte TG, van Eijsden M. Maternal early pregnancy vitamin D status in relation to fetal and neonatal growth: results of the multi-ethnic Amsterdam Born Children and their Development cohort. Br J Nutr. 2010;104(01):108-17.

33. Wagner CL, McNeil R, Hamilton SA, Winkler J, Rodriguez Cook C, Warner G, et al. A randomized trial of vitamin $D$ supplementation in 2 community health center networks in South Carolina. Am J Obstet Gynecol. 2013;208(2):137.e1-.e13. doi:10.1016/j.ajog.2012.10.888.

34. Bergen $\mathrm{N}$, Jaddoe $\mathrm{V}$, Timmermans $\mathrm{S}$, Hofman A, Lindemans J, Russcher $\mathrm{H}$, et al. Homocysteine and folate concentrations in early pregnancy and the risk of adverse pregnancy outcomes: the Generation R study. BJOG. 2012;119(6):739-51.

35. Yajnik CS, Chandak GR, Joglekar C, Katre P, Bhat DS, Singh SN, et al. Maternal homocysteine in pregnancy and offspring birthweight: epidemiological associations and Mendelian randomization analysis. Int J Epidemiol. 2014;43(5):1487-97.

36. Torres-Sánchez L, López-Carrillo L, Blanco-Muñoz J, Chen J. Maternal dietary intake of folate, vitamin B12 and MTHFR 677C> T genotype: their impact on newborn's anthropometric parameters. Genes Nutr. 2014;9(5):1-9.

37. Rush EC, Katre P, Yajnik CS. Vitamin B12: one carbon metabolism, fetal growth and programming for chronic disease. Eur J Clin Nutr. 2014;68(1):2-7. doi:10.1038/ejcn.2013.232.

38. Dwarkanath P, Barzilay JR, Thomas T, Thomas A, Bhat S, Kurpad AV. High folate and low vitamin B-12 intakes during pregnancy are associated with small-for-gestational age infants in South Indian women: a prospective observational cohort study. Am J Clin Nutr. 2013;98(6):1450-8

39. Ahmed A, Akhter M, Sharmin S, Ara S, Hoque MM. Relationship of Maternal Folic Acid and Vitamin B12 with birth weight and body proportion of newborn Journal of Dhaka National Medical College \& Hospital. 2012;18(1):7-11.

40. Sukla KK, Tiwari PK, Kumar A, Raman R. Low birthweight (LBW) and neonatal hyperbilirubinemia (NNH) in an Indian cohort: association of homocysteine, its metabolic pathway genes and micronutrients as risk factors. PLoS One. 2013;8(8):e71587.

41. Muthayya S, Kurpad A, Duggan C, Bosch R, Dwarkanath P, Mhaskar A, et al. Low maternal vitamin B12 status is associated with intrauterine growth retardation in urban South Indians. Eur J Clin Nutr. 2006;60(6):791-801.

42. Abraham A, Mathews JE, Sebastian A, Chacko KP, Sam D. A nested case-control study to evaluate the association between fetal growth restriction and vitamin B12 deficiency. Aust N Z J Obstet Gynaecol. 2013;53(4):399-402.

43. Gadgil M, Joshi K, Pandit A, Otiv S, Joshi R, Brenna JT, et al. Imbalance of folic acid and vitamin B12 is associated with birth outcome: an Indian pregnant women study. Eur J Clin Nutr. 2014;68(6):726-9. doi:10.1038/ ejcn.2013.289.

44. Hogeveen M, Blom HJ, van der Heijden EH, Semmekrot BA, Sporken JM, Ueland PM, et al. Maternal homocysteine and related B vitamins as risk factors for low birthweight. Am J Obstet Gynecol. 2010;202(6):572. e1-e6.

45. Halicioglu O, Sutcuoglu S, Koc F, Ozturk C, Albudak E, Colak A, et al. Vitamin B12 and folate statuses are associated with diet in pregnant women, but not with anthropometric measurements in term newborns. J Matern Fetal Neonatal Med. 2012;25(9):1618-21.

46. Bergen N, Jaddoe V, Timmermans S, Hofman A, Lindemans J, Russcher $\mathrm{H}_{\text {, }}$ et al. Homocysteine and folate concentrations in early pregnancy and the risk of adverse pregnancy outcomes: the Generation R study. Obstet Anesth Dig. 2013;33(2):111-2.

47. Prentice A. Micronutrients and the bone mineral content of the mother, fetus and newborn. J Nutr. 2003;133(5):1693S-9S.

48. Doyle W, Crawford M, Wynn A, Wynn S. Maternal magnesium intake and pregnancy outcome. Magnes Res. 1989;2(3):205-10.

49. Tobias J, Steer C, Emmett P, Tonkin R, Cooper C, Ness A. Bone mass in childhood is related to maternal diet in pregnancy. Osteoporos Int. 2005;16(12):1731-41.
50. Jones $\mathrm{G}$, Riley M, Dwyer T. Maternal diet during pregnancy is associated with bone mineral density in children: a longitudinal study. Eur J Clin Nutr. 2000;54(10):749-56.

51. Bo S, Pisu E. Role of dietary magnesium in cardiovascular disease prevention, insulin sensitivity and diabetes. Curr Opin Lipidol. 2008;19(1):50-6.

52. Rayssiguier $Y$, Gueux E, Nowacki W, Rock E, Mazur A. High fructose consumption combined with low dietary magnesium intake may increase the incidence of the metabolic syndrome by inducing inflammation*. Magnes Res. 2006;19(4):237-43.

53. King DE, Mainous III AG, Geesey ME, Ellis T. Magnesium intake and serum C-reactive protein levels in children. Magnes Res. 2007;20(1):32-6.

54. King DE. Inflammation and elevation of C-reactive protein: does magnesium play a key role? Magnes Res. 2009;22(2):57-9.

55. He K, Liu K, Daviglus ML, Morris SJ, Loria CM, Van Horn L, et al. Magnesium intake and incidence of metabolic syndrome among young adults. Circulation. 2006:113(13):1675-82.

56. Martinez A, Santiago J, Varade J, Marquez A, Lamas J, Mendoza J, et al. Polymorphisms in the selenoprotein $S$ gene: lack of association with autoimmune inflammatory diseases. BMC Genomics. 2008:9(1):329.

57. Duntas L. Selenium and inflammation: underlying anti-inflammatory mechanisms. Horm Metab Res. 2009:41(6):443-7.

58. Tanguy S, Rakotovao A, Jouan M-G, Ghezzi C, de Leiris J, Boucher F. Dietary selenium intake influences Cx43 dephosphorylation, TNF-a expression and cardiac remodeling after reperfused infarction. Mol Nutr Food Res. 2011;55(4):522-9. doi:10.1002/mnfr.201000393.

59. Campa A, Baum MK. Role of selenium in HIV/AIDS. Selenium. New York: Springer; 2012. p. 383-97.

60. Kibriya MG, Jasmine F, Argos M, Verret WJ, Rakibuz-Zaman M, Ahmed A, et al. Changes in gene expression profiles in response to selenium supplementation among individuals with arsenic-induced pre-malignant skin lesions. Toxicol Lett. 2007;169(2):162-76.

61. Bogden JD, Kemp FW, Chen X, Stagnaro-Green A, Stein TP, Scholl TO. Low-normal serum selenium early in human pregnancy predicts lower birth weight. Nutr Res. 2006;26(10):497-502.

62. Klapec T, Ćavar S, Kasač Z, Ručević S, Popinjač A. Selenium in placenta predicts birth weight in normal but not intrauterine growth restriction pregnancy. J Trace Elem Med Biol. 2008;22(1):54-8.

63. Mistry HD, Kurlak LO, Young SD, Briley AL, Broughton Pipkin F, Baker PN et al. Maternal selenium, copper and zinc concentrations in pregnancy associated with small-for-gestational-age infants. Matern Child Nutr. 2012;10(3):327-34

64. Tan M, Sheng L, Qian Y, Ge Y, Wang Y, Zhang H, et al. Changes of serum selenium in pregnant women with gestational diabetes mellitus. Biol Trace Elem Res. 2001;83(3):231-7.

65. Al-Saleh E, Nandakumaran M, Al-Shammari M, Al-Harouny A. Maternal-fetal status of copper, iron, molybdenum, selenium and zinc in patients with gestational diabetes. J Matern Fetal Neonatal Med. 2004;16(1):15-21.

66. Askari G, Iraj B, Salehi-Abargouei A, Fallah AA, Jafari T. The association between serum selenium and gestational diabetes mellitus: a systematic review and meta-analysis. J Trace Elem Med Biol. 2015;29:195-201.

67. Gazala E, Sarov B, Hershkovitz E, Edvardson S, Sklan D, Katz M, et al. Retinol concentration in maternal and cord serum: its relation to birth weight in healthy mother-infant pairs. Early Hum Dev. 2003;71(1):19-28.

68. Ghebremeskel K, Burns L, Burden T, Harbige L, Costeloe K, Powell J, et al. Vitamin $A$ and related essential nutrients in cord blood: relationships with anthropometric measurements at birth. Early Hum Dev. 1994;39(3):177-88.

69. Shah R, Rajalakshmi R. Vitamin A status of the newborn in relation to gestational age, body weight, and maternal nutritional status. Am J Clin Nutr. 1984;40(4):794-800.

70. Tielsch JM, Rahmathullah L, Katz J, Thulasiraj R, Coles C, Sheeladevi S, et al. Maternal night blindness during pregnancy is associated with low birthweight, morbidity, and poor growth in South India. J Nutr. 2008;138(4):787-92.

71. Watson P, McDonald B. The association of maternal diet and dietary supplement intake in pregnant New Zealand women with infant birthweight. Eur J Clin Nutr. 2009;64(2):184-93. 
72. Mathews F, Youngman L, Neil A. Maternal circulating nutrient concentrations in pregnancy: implications for birth and placental weights of term infants. Am J Clin Nutr. 2004;79(1):103-10.

73. Wang $Y-Z$, Ren $W-H$, Liao W-q, Zhang G-Y. Concentrations of antioxidant vitamins in maternal and cord serum and their effect on birth outcomes. J Nutr Sci Vitaminol. 2009:55(1):1-8.

74. Doyle W, Crawford M, Wynn A, Wynn S. Maternal nutrient intake and birth-weight. J Hum Nutr Diet. 1989;2(6):415-22.

Submit your next manuscript to BioMed Central and take full advantage of:

- Convenient online submission

- Thorough peer review

- No space constraints or color figure charges

- Immediate publication on acceptance

- Inclusion in PubMed, CAS, Scopus and Google Scholar

- Research which is freely available for redistribution 